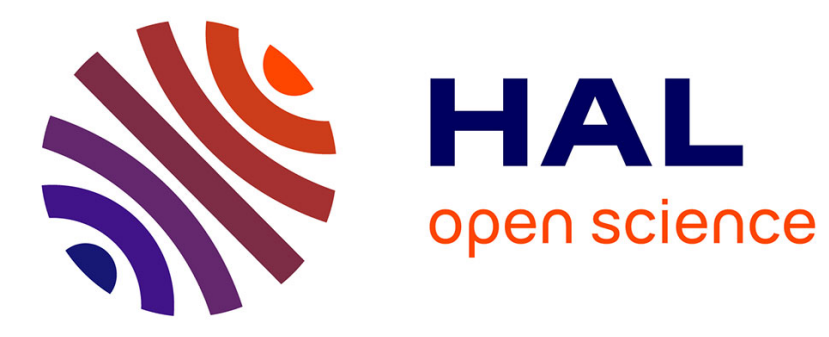

\title{
The futures of the service economy in Europe: a foresight analysis
}

\author{
Faïz Gallouj, Matthias Weber, Metka Stare, Luis Rubalcaba
}

\section{To cite this version:}

Faïz Gallouj, Matthias Weber, Metka Stare, Luis Rubalcaba. The futures of the service economy in Europe: a foresight analysis. Technological Forecasting and Social Change, 2015, pp.TSF-18028. halshs-01133897

\section{HAL Id: halshs-01133897 https://shs.hal.science/halshs-01133897}

Submitted on 24 Mar 2015

HAL is a multi-disciplinary open access archive for the deposit and dissemination of scientific research documents, whether they are published or not. The documents may come from teaching and research institutions in France or abroad, or from public or private research centers.
L'archive ouverte pluridisciplinaire HAL, est destinée au dépôt et à la diffusion de documents scientifiques de niveau recherche, publiés ou non, émanant des établissements d'enseignement et de recherche français ou étrangers, des laboratoires publics ou privés. 


\title{
(Published in Technological Forecasting and Social Change)
}

\section{The futures of the service economy in Europe: a foresight analysis}

Faïz Gallouj, Professor, University Lille 1, CLERSE-CNRS, France.

Matthias Weber, Deputy Head of Department, Austrian Institute of Technology (AIT), Foresight and Policy Development Department, Austria.

Metka Stare, Research Professor, University of Ljubljana, Faculty of Social Science, Slovenia.

Luis Rubalcaba, Professor, University of Alcala, Applied Economics Department, Spain.

\begin{abstract}
.
The paper presents a signalling exercise with a view to trace emerging dynamics in the development of the services economy in Europe. These dynamics have a direct influence and will trigger off service innovation. Firstly, the drivers of the service economy are presented, many of them fostering service innovation as a way to face new societal and business challenges. Secondly, emerging developments are discussed to identify the most promising service innovation dynamics. Finally, foresight scenarios demonstrate possible future trends of the new service economy. These scenarios are based on a methodology developed and applied in the context of an EC-funded project on Sectoral Innovation Systems. This exercise is performed for the overall set of services activities although a particular focus is given on activities such as knowledge intensive business services and distributive trade services. Results indicate that emerging developments are those related to the reconciliation between industrialisation and customisation associated with ICT, ageing population, sustainable development and service regression and extension dynamics. The cases of knowledge intensive services and distributive trades have shown how different drivers and emerging developments are interrelated and establish different scenarios for future development.
\end{abstract}

\section{Key words:}

Services, Future, Foresight, Europe, Knowledge-Intensive Services, Wholesale and Retail Trade 


\section{Introduction}

As the service component of production and consumption of the European economies continues to grow, alongside with the increasing share of workforce employed in service activities, new developments are emerging that will drive and shape service innovation and consequently also the future of service economy. Both are inextricably linked since the future service economy will critically depend on innovation in service sectors and service activities throughout the economy and society. More than ever services are interrelated and integrated to all economic activities, public institutions, civil society organisations and individuals' life (European Commission, 2013a). In this sense, signalling the drivers that will influence service economy includes not only the anticipation of changes in service industries but also the indication of possible socioeconomic transformations where services and service systems will play a key role, due to the complex interlinkages they create among stakeholders. Most of those drivers of change are of general nature influencing service economies on a global scale, while some of them will have larger impact in Europe. Given the dominant weight of services in economic and social tissue, futures studies of service economy are indispensable to inform the stakeholders about the sources of changes in socio-economic environment and also to induce policy makers to respond to them. All the more so if we concur with the assessment that in the present period the pace of social change is overtaking the pace of radical technological innovation (Phillips, 2011). This pace is revealed in services dynamics affecting sectors such as the IT outsourcing services (Sharma, 2013), the mobile service platforms (de Reuver at al., 2011) or the transport industry (Godet, 1994, 2006).

The aim of the article is to explore emerging developments in the service economy. Terminology, conceptual and methodological approaches to dealing with future and emerging developments are fairly diversified (Naisbitt, 1982; Slaughter, 1996; Martin and Johnston, 1999; Miles 2010; Saritas and Nugroho, 2012). While it is common to refer to trends and drivers as main determinants of change, there is a lot of confusion about the use of these terms. Kuosa (2010) has suggested a framework to systematize the language for understanding the future. He distinguishes first of all weak signals, which are highly uncertain, tacit and subjective indications of potential future developments that are foreshadowed by rather isolated present-day observations. Secondly, drivers are a more structured form of information that allows inferring causalities but is still subject to a significant degree of uncertainty. Trends are the most explicit and objective form of information, because they are built on past observations and their regularities. ${ }^{1}$ All three types of information about the future can be either disruptive or promoting the current situation; a distinction that is very important when it comes to analyzing the consequences and impacts of trends, drivers and weak signals.

This framework may be a very useful one, but it is not uncontested. Saritas and Smith (2010), for instance, use a very different way of distinguishing trends and drivers, by referring to the extent to which a development can be influenced by the actors in a certain area or not. From a systems perspective, an actor can exert an influence on the developments within a specific system boundaries ("drivers", according to Saritas and Smith), but not on the wider external socio-

\footnotetext{
${ }^{1}$ Emerging developments are then just a specific form of higher-order driver with likely major or even pervasive effects (Kuosa, 2010).
} 
economic developments that also influences the system change ("trends"), because they are well beyond the influence of the actors in a system.

For the purpose of exploring emerging developments in the service economy, we build on Kuosa (2010), but refer mainly to the notion of trends and drivers. We also follow the argumentation of Vecchiato and Roveda (2010), who have been investigating the impact of drivers of change on sectors and the position of corporate organisations in these. They distinguish state uncertainty (about the emergence of certain drivers) and effect uncertainty (about the impact of certain drivers). ${ }^{2}$ This distinction is important in our context as we are particularly interested in the impact or effect of certain drivers on the future service economy. Drivers are seen as shaping the development of the system under study, i.e. the service economy. Trends, following Kuosa (2010) are then nothing else than the more certain and objective among the drivers. The more uncertain these drivers are (and thus the less trend-like) the more diverse are the possible patterns of development of the system under study, thus pointing to the need to develop a range of scenarios.

A methodological consequence of Vecchiato and Roveda (2010) is what they call "putting the drivers first", i.e. to start a forward-looking activity with an exploration of drivers, and in particular with the exploration of the transformative implications that these drivers may have on an industry and thus for the strategic options of a corporate organisation ("anticipatory approach"). Their approach stresses the strategic importance of potential discontinuous changes and can be contrasted with a trends-based approach ("sustaining approach") that relies on extrapolation and trend analysis rather than on the potential for discontinuous change.

Applied to an exploration of emerging developments in the service economy, a further specificity needs to be taken into account, because the emerging development patterns may vary quite significantly across service sub-sectors, depending on the specificities of these sub-sectors. This is why we apply the methodological element of scenario development to the exploration of specific such sub-sectors, even if we can build on joint drivers and emerging developments in the service economy at large. Two such subsectors are explored in more detail, namely Wholesale and Retail Trade (WRT), and Knowledge Intensive Business Services (KIBS).

There is an important link with innovation to be considered. The service economy at large, or specific sub-sectors thereof, such as KIBS or WRT, can be regarded as innovation systems in the sense of Malerba's (2005) Sectoral Systems of Innovation and Production (SSIP). The scenarios thus correspond to the future projections of such SSIP. With regard to innovation, this implies that each scenario describes a different future manifestation of the service sub-sector in question, in which specific service innovations are realized. Each scenario is associated with (i.e. it favours or requires) different types of specific innovations in services. Some of these innovations may be 'safe bets' in the sense that they are likely to arise in different scenarios of that specific subsector (robust innovations), while others are specific for certain scenarios only.

\footnotetext{
${ }^{2}$ Vecchiato and Roveda (2010) also distinguish response uncertainty, i.e. the uncertainties associated to the strategic responses of corporate organisations, but this is less relevant in our context. See also Milliken (1987).
} 
Alongside changes in the conceptualisation and scope of futures studies, the evolution of methodological approaches also reflects the increasing complexity of the phenomena and demonstrates the progress from simple tools and techniques, to more sophisticated methods, such as network analysis and systemic thinking. Methodological approaches to future studies differ along several characteristics, but major distinction is between qualitative and quantitative methods where the former rely on intuition, invention, hypothesis, and judgment. The selection of method for individual futures study depends on the context, issue studied, the budget, time available, etc. (Puglisi, 2001) in a context dominated by an eclectic flexibility in methods and techniques used especially by American futurists (Coates, 2010). Our conceptual and methodological approach to anticipating the futures of service economy is limited to identifying the main drivers that will underpin the evolution of service economy and to illustrating the combinations of those drivers that lead to trends in services development in the near future. The methodological approach used in the paper is based on expertise and qualitative analysis, detection and scanning of emerging issues that will shape service economy in future. The selection of drivers and trends used in this paper has been the result of the authors' research work within FP7 project on services and services innovation (ServPPIN, 2011), including 45 case studies in different services sectors and more than 20 cross-sectoral reports on various service innovation topics. Informed by these results we examine how could the combination of several drivers result in emerging developments that cause radical socio-economic changes. Concrete examples of four emerging developments serve to illustrate the type of innovation they trigger. In view of the large heterogeneity of services it could be expected that impacts of drivers would display large differences between service sectors; an exercise that goes beyond the purpose of this paper. Focusing on possible scenarios in only two sub-sectors of services - knowledgeintensive business services and wholesale and retail distributive trade still enables to reveal the role and interplay of drivers and trends that will determine future evolution of those two highly relevant service subsets. In this part we rely on the findings of the EU research project Sectoral Innovation Watch under Europe Innova (European Commission, 2007, 2013b) to highlight few scenarios on how KIBS and WRT may evolve in the future.

In line with the above methodology the article is structured as follows. After the introduction the main drivers of change affecting the service economy are analysed (section 2). Section 3 concentrates on the major emerging developments in the service economy that we can identify under the influence of the different drivers. These future developments are then further exemplified for the two sub-sectors WRT and KIBS (section 4). The concluding section summarizes the major findings of the futures analysis of the service economy. It proposes some areas for future research and conveys to policy makers early signals on prospective developments in service economy.

It is important to state that the drivers and emerging developments analyzed in detail are the most important ones following the results of the projects mentioned above. They do not pretend to cover all possible elements. Moreover, along the text on emerging developments in services (section 3), the four major drivers identified (in section 2) are complemented by additional drivers that may have particular impacts on individual emerging developments. Furthermore, in certain cases, we focus only on one special dimension (or a limited number of dimensions) of a given generic driver. In the same line, the major emerging developments identified (in section 3 ) 
are the basis for undertaking the scenarios analyses in (section 4), but these cover specific additional elements for the selected sectors. The paper does not intend to explain the full set of complex interactions between the different drivers and the emerging developments, but to report just the most relevant ones for understanding the service dynamics in the context of the futures exercise we develop.

\section{The drivers of change in service economy}

While the identification of main determinants of services growth in the past builds on solid empirical data, the exploration of drivers that will influence future developments relies on extrapolation of current changes and detected signals of change that may evolve into trends of services growth and development. Based on the track record of the authors' research experience and expertise in the field of services research and taking into account insights from some recent documents and studies (European Commission, 2013a), we suggest a set of drivers and their interactions that will have a profound impact on future service economy.

\subsection{The transformative power of new technologies, human capital and changes in productive systems}

The integrated treatment of the three drivers points to inextricable interaction among them. ICT and increased complexity of the productive systems trigger the need for new knowledge and specialized skills to deal with the integration of new technology into businesses and the public sector. By and large, ICT has become one of the major driving forces of services development that transforms traditional services, generates a variety of new services and changes the channels of services delivery. There is hardly any service (but also non-service activity) that has not been affected by ICT directly or indirectly.

Emerging technologies are opening avenues for new services and innovative business models to companies and final consumers. Collaborative Web 2.0 and Web 3.0 technologies, such as wikis, cloud computing, mash-ups, mobile Internet, living labs, social networking, and others encourage open service innovations that reshape not only businesses, public services and leisure time of individuals, but also the way how knowledge is created, produced and disseminated; how employees communicate within business environment and how citizens interact with other citizens or institutions. The Internet of Things points to multiple use opportunities of connecting objects to the Internet. In parallel, it may as well increase the risks for citizens' health, privacy and data protection (European Parliament, 2010). Other technologies, such as for example biotechnology and nanotechnology and their integration/convergence may induce the emergence of novel services or new providers of services that will contribute to economic growth, to coping with big societal challenges (e.g. ageing population, renewable energy, drinking water, climate change, etc.) or catering to individuals' preferences for services provision (e.g. DNA analysis on demand). More sophisticated 3-D printing using new ultra compact materials will transform manufacturing and give impetus to printing services and applications of new business models. The arrival and broader use of new technologies also reinforces the demand for existing services that could help in addressing related threats and increased risks (e.g. services dealing with security, privacy, identity theft, manipulation of nature, health). 
Even though the availability of sophisticated technical skills may prevail in generating some services, soft skills and social sciences related knowledge is of utmost importance to integrate and use efficiently new technologies. Knowledge intensive business services and organisational innovations will play an essential role in translating the potential of new technology into business results and improved welfare. Identifying and solving the problems of final and business users will be at the core of innovation activities. The demand for special expertise, consultancy, and "systems integration" services will increase. The convergence of technologies will exert strong pressure on education system towards re-skilling and life-long learning of active population on one hand, and towards interdisciplinary education and training on the other hand. Universities are already transforming their portfolio by adding massive open online courses to traditional classroom courses (e.g. Coursera ${ }^{3}$ that connects prominent universities and institutes from around the globe that jointly offer free online courses). Other new providers are emerging, such as "business-driven education networks". Further disruptions in the provision of high quality inexpensive education services will come from easy global access via mobile online learning (Tow, 2012). Open principles of collaboration, facilitated by Web 2.0 and Web 3.0 tools encourage companies to combine internal and external sources of knowledge on a global scale. Yet, it could be difficult to control the proprietary knowledge and expertise of companies in new business models (Chesbrough and Schwartz, 2007). Further risks and challenges of new technologies and interactive applications are to be expected in regard of the skills gap and potential exclusion of a large part of the population from the benefits of technologies. This calls for massive re-training and the provision of life-long learning that will "democratize" the use of modern technologies. Increasingly, social innovations are emerging in education and training that enable deprivileged parts of the population to engage in the learning processes in nonconventional ways.

Even if unrestricted deployment of new technologies for the benefit of all actors may seem quite unchallenged, these developments could as well be interrupted. Unexpected events, such as Wikileaks or threats related to possible abuse of new technologies having adverse effects on certain interest groups (e.g. big multinational companies, institutions or policy makers), individuals or the humanity in general may reverse or slow-down deployment of new technologies. The openness of collaboration could be limited to authorized actors, some activities regulated or re-regulated.

\subsection{The transformation and globalisation of markets}

Competitive pressures associated with market globalization are changing the relationships among companies, increasing the need for modernization and cooperation with partners and competitors. ICT has increased the tradability of services and opened ways for new business models and offshoring where service providers are able to serve clients globally. Services internationalisation is increasingly taking place via foreign direct investment that facilitates tradability of services and simultaneous presence of suppliers and consumers. In 2008 services accounted for $65 \%$ of the total stock of outward FDI with the dominant weight of financial and business services (WIR, 2010) that decreased somewhat in 2009 and 2010, but recovered in 2011 (WIR, 2012). Services assume complex and multiple roles in internationalisation. They enable the globalization by establishing transport and communication networks; business and financial services support the

\footnotetext{
${ }^{3}$ https://www.coursera.org/
} 
internationalization of companies; consumer services, such as audiovisual and cultural services, tourism-related services, distributive trades or e-commerce services are offered on a global scale.

Globalisation could become a much more potent source of services growth and service innovation for Europe given the forecast that the emerging-market economies (EME) will be the major generators of economic growth in the next decade (McKinsey, 2010). It can be anticipated that demand patterns in those economies will increasingly change in favour of intermediate and final services as they progress along the development path. EME will strengthen the supply of various services to meet increasing local demand and also to make bolder inroads into international markets. The upsurge of demand for services in EME may provide impetus and opportunities for European service providers to engage in export and FDI in various business related or final consumption services. Demand will increase for innovative energy services, for a range of environmental services, but also for travel, and "packages of experience services". On the other hand, competitive suppliers of services from EME will provide both knowledge intensive services to European businesses through offshoring and low paid manual services to consumers, particularly those related to ageing population care, provided the easing of labour entry restrictions for immigrants. One should not neglect the potential of inclusive innovations ${ }^{4}$, also called Ghandian innovations or Innovation 2.0 that took off particularly in India. The essence of inclusive innovation is to produce more $(\mathrm{M})$ performance with less (L) resources for more (M) people (MLM) (Prahalad, Mashelkar, 2010). Apart for low cost Tata car Nano that is affordable to large segment of the population, inclusive innovation has resulted in a number of innovative solutions in ICT based services and health services (e.g. cataract surgery) that are disruptive in a sense that they could change the relations among stakeholders on a global scale. Inclusive innovation may be a challenging opportunity for European businesses to better align to the needs of low-income population in EME and benefit from scale economies.

\subsection{The changing role of the State}

The public sector is both provider and consumer of services. It also indirectly affects the growth of service sectors by introducing regulation or easing existing regulation (deregulating). Legal consultancy, accountancy, tax counselling, audit, food safety, product or environment quality services would not have developed to such an extent if it had not been for coercive, obligatory rules. Since the beginning of the 1980s deregulation of service sectors played the enabling role in introducing more flexible and competition-friendly regimes to mitigate entry barriers, red-tape or legal requirements that hinder competition and economic performance (Nicoletti and Scarpetta, 2003; Barone and Cingano, 2008). It is expected that further liberalisation and gradual implementation of Service Directive will give rise to freer flow of services within the EU and consequently contribute to economies of scale in some service sectors. However, without further

\footnotetext{
${ }^{4}$ According to Global Research Alliance "inclusive innovation refers to the knowledge creation, acquisition, absorption and distribution efforts targeted directly at meeting the needs of the low-income population". The focus of Inclusive Innovation is on delivering high performance products and services or high experience at ultra-low cost to the people whose needs are generally not addressed http://www.theglobalresearchalliance.org/What-wedo/Inclusive-Innovation.aspx
} 
coordination of policies in other areas (e.g. tax policy, labour market policy, etc.) the anticipation of efficient roll out of the benefits of internal market for services could turn out unrealistic.

Current economic crisis that partly originates in inadequate regulation and/or supervision of financial services urges the revamping of regulation. Strict supervision may temporarily affect innovation dynamic in "core" financial services, however innovation may appear in supplementary services that link the providers of financial services with other service industries (e.g. retail) in order to meet better the consumer's needs. Novel ways of financing start-ups and other enterprises are emerging as a response to limited bank lending (e.g. crowdfunding, social funds). Another area where re-regulation is likely to appear refers to environmental protection and related services. Environment friendly regulation will foster businesses to look for innovative solutions (e.g. technical engineering and green consultancy services) and enhance the shift in consumers' behaviour towards the use of greener services (e.g. public transport with low carbon emissions). Deregulation or re-regulation may also boost health care services aimed at addressing ageing population problems. Networks of public health system institutions and civil society organisations could provide new organisational models and networks for elderly care services, extensively relying on new technologies, open service innovation and social innovation.

Big challenges and risks for regulatory involvement of the state arise from new technologies. On one hand they create immense opportunities for businesses and well-being of citizens, but on the other hand they increase the risks for individuals and society at large. There is a need for smart regulation that will strike a proper balance between leveraging the potential of new technologies and prevent the abuse or safeguard privacy and security of citizens.

\subsection{Societal and environmental challenges}

In recent decades improved working conditions, higher living standard and better health services, including the advancement in health technology have increased life expectancy, contributing to the ageing of the European population. Higher demand of this segment of population for various services is already the case and traditional institutional arrangements prove to be insufficient. New providers of services, including private suppliers and civil society organisations, are becoming important actors in providing alternative solutions in the institutional setup. Partnerships between actors from public and private sector, non-profit organisations and civil society are likely to be formed to supply requisite services. Ageing population is not a homogenous group in terms of income, education level, physical and health status, place of living (urban/rural) and even age range opening plenty of room for diversified niche services to cater to special needs of those sub-groups. Irrespective of the type of services, service design will become the key element of innovative services to address the of changed demography.

Furthermore, the power of "conscious consumers" as individuals, civil society actors or social entrepreneurs will increasingly shape the demand beyond niche markets. Innovative services will complement innovative technologies, provide solutions for greener production and consumption and address pertinent problems of waste management, clean water provision, rehabilitation of degraded lands, etc. The above trends will open up large business opportunities for European companies to supply new services, create partnerships and networks, where complementarities among stakeholders are mutually reinforcing and enhance learning. Scaling of bottom up initiatives by small businesses and/or local communities that deal with environmental threats 
could bring potent solutions on a larger scale. Finally, formal and informal education and training will play a prominent role in raising the awareness on sustainable production and consumption and acknowledging that costs along "the value creation, consumption and recycling" matter in any profit and non-profit undertakings.

Disruptive technologies are expected to provide valuable solutions to problems, but will not be able to cope with fundamental issues of societal transformation, where service innovation could make important contribution to social shaping of technologies through new organizational approaches and business models. Addressing the societal and environmental challenges will progressively postulate new approaches to their solution, new roles and interactions of various stakeholders' resulting in social innovation ${ }^{5}$.

In the above section, we addressed the main external generic drivers of the service economy and of innovation in services. Considered individually these drivers may lead to incremental as well as to radical innovations. In reality, it is seldom the case that any of these different drivers comes into play in isolation. They interact in different ways, either mutually reinforcing or outweighing each other. The combination of several drivers gives rise to a set of important emerging developments in services that we discuss in the following section.

\section{Emerging developments in the service economy}

The emerging developments in question can be described in various ways. The number of drivers involved in shaping emerging developments can vary; they can be more or less numerous. They can be located on the supply as well as on the demand side, and they can be institutional in nature (Saritas and Smith, 2011). The interplay of these drivers in time can differ; they can occur simultaneously, but also be connected through a causal relationship. The relative weight of these drivers can vary, and they can both complement or compete with each other so contradictory effects can co-exist within a given trend (or anti-trend in the Kuosa terminology, see Kuosa, 2010).

In the reminder of this section we examine a set of emerging developments which seem to be particularly important in the field of services and innovation in services. Some of them are not new, but they are far from exhausted. This applies, for example, in numerous services activities, to the dialectic relationship between industrialisation and customisation (emerging development 1). This is also the case with the emerging development based on service regression and extension (emerging development 2). Other cases are more recent and not yet recognised, as they should be. This is, for example, the case of the emerging development based on population ageing (emerging development 3) or on sustainable development (emerging development 4). It should be acknowledged that these four emerging developments do not involve the same analytical levels. The two first ones are dichotomic and they describe the change of general service practices, while the others describe more specific content in services. Therefore, they are

\footnotetext{
5 "Social innovation seeks new answers to social problems by identifying and delivering new services that improve the quality of life of individuals and communities" (Business panel on future EU innovation policy, 2009).
} 
not completely independent of each other. For example, innovation logics which are occurring in emerging development 1 (the reconciliation of industrialization and customisation) and emerging development 2 (service regression and extension) are also likely to be involved in emerging development 3 (based on population ageing). We will discuss each of these emerging developments according to the three following perspectives and emphasizing the third one: i) the essence of the emerging development, ii) its underlying drivers, iii) its manifestations and especially examples of innovations associated to it.

\subsection{Emerging development 1: The reconciliation of industrialisation and customisation of services}

The essence of the emerging development

For long time services have been characterised by a tension between industrialisation and customisation, between repetition and personalisation (Gallouj, 2002; Rubalcaba, 2007). Some services are defined by a high degree of personalisation (consultancy, personal services) while others are highly standardised (transport, communications) and many have to decide between degrees of one side or the other. What is new is that new less dialectic balances are possible, which means that the same firms and organisations or the same sectors often implement both strategies simultaneously. There is a reconciliation between industrialisation and customisation. Considered independently, industrialisation and customisation are two important trajectories of innovation in services. Nevertheless their combination provides the basis of this important first emerging development trend.

\section{Underlying drivers}

The underlying drivers of this first emerging development may be different from one sector to another (at least in their relative importance). They include the drivers associated with the industrialisation trend, the drivers associated with the customisation trend and those associated with the reconciliation of both trends, although it is not always easy to separate them. These drivers include market globalisation, increasing competition, standards, new role of state, societal challenges, non-ICT technologies. However among these drivers ICTs always play a prominent role in the integration of industrialisation and customisation. Computerisation in its decentralised, networked form can be seen as a fundamental factor in integrationist (reconciliation) strategies, serving as a basis both for 'servicisation' processes assisted by decentralised computer systems and for more standard industrialisation processes associated with back-office computer systems. This integrative role of ICTs is particularly relevant in informational services such as banking, insurance and a large part of public services, but it is also at work in other types of services. This is the case of retailing (cf. section 4) where the use of ICTs allows the addition of new delivery concepts. IT literacy also plays a role in this emerging development as far as IT illiteracy and digital divide are obvious impediments to such new service delivery formula (teleservices in general). 


\section{Emerging development - Case 1: Reconciliation of industrialisation and customisation}

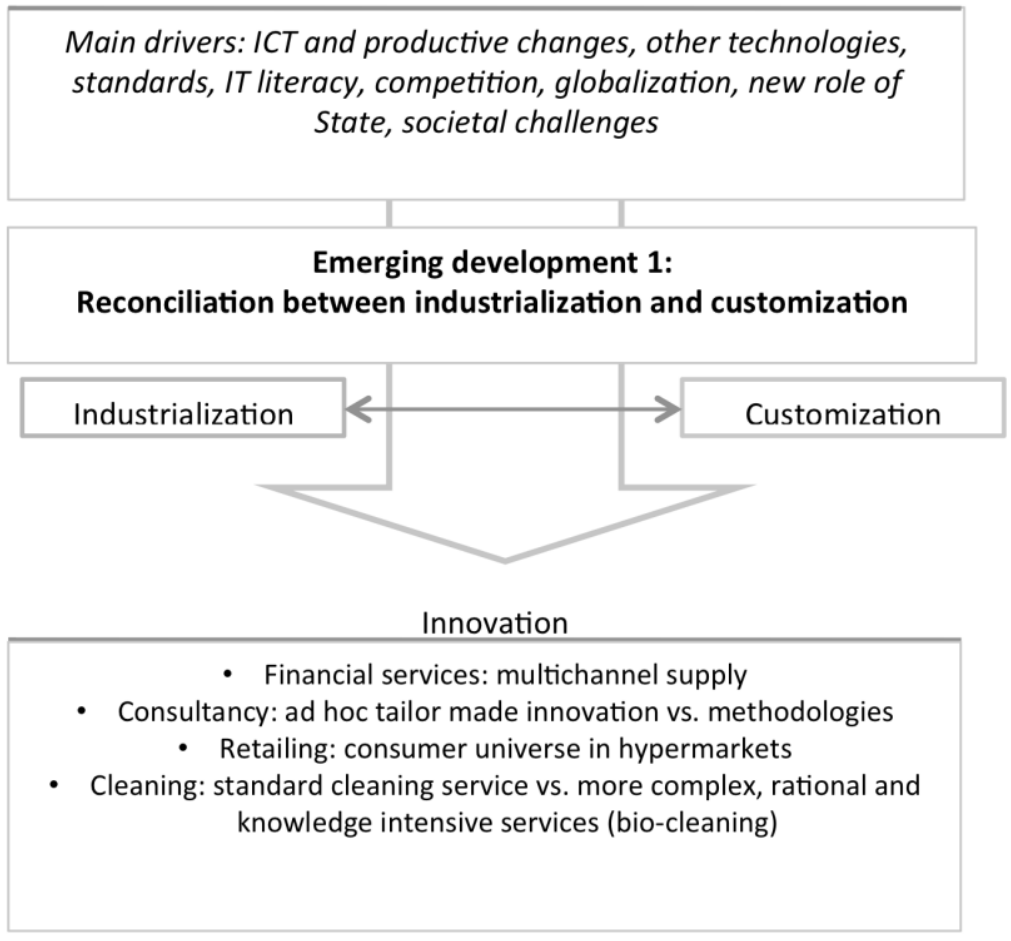

\section{Manifestations of the emerging development}

Firms can simultaneously adopt opposing industrialisation and customisation strategies. This is what we denote here by the term integration strategies (Gallouj, 2002). Such strategies are particularly common in large companies in the banking, insurance, retail and distribution, tourism and transport sectors, for example. Strategies which, at certain times (today in particular), have been described as integration strategies are in reality frequently part of a historical process that has unfolded in two successive phases, the first dominated by industrialisation strategies and the second by customisation strategies, reflecting the rise to prominence of the service dimension.

The dialectic between industrialisation and servicisation is particularly evident in financial services. Large banks and insurance companies combine standardised quasi-products and automated self-service, on the one hand, with 'high value-added' and tailor-made services, on the other hand. The latter are developed in the context of highly interactive service relationships in which customers play an active role. The first alternative reflects a strategy based on industrial rationalisation, the second one a strategy based on professional rationalisation, in which standardisation is rejected in favour of the development of problem-solving methods (in the style of consultants' methodologies).

Another example is retailing. Examination of the long-term evolution of the retail and distribution sector shows that, from the 1940s and 50s in the USA and from the 1970s in European countries supermarkets followed a natural technological trajectory of increasing mechanisation and economies of scale based on two fundamental innovations: self-service and the establishment of chains of stores. For a long time, the innovation model at work focused 
essentially on the materials logistics function (introduction of Fordist logistical systems) and on strengthening the self-service relationship and then, in a second phase, on the information logistics function. For some years in the USA, and more recently in Europe, change in the retail and distribution sector has taken two new directions, which do not exclude the previous one, both of which fall within the scope of a servicisation dynamic: 1) the provision of new "experience services" (for example, consumer universe in supermarkets); 2) the improvement of service relationships through the introduction of loyalty and credit cards and other benefits for loyal customers.

\subsection{Emerging development 2: The service regression vs. the service extension dynamics}

\section{The essence of the emerging development}

While the previous emerging development (the reconciliation of industrialisation and customisation) basically involves the reorganisation of service provision, this second emerging development involves an evolution (positive or negative) of the range of the services on offer. From the theoretical point of view, this second emerging development (which is closely linked to the first one) is based on the idea that a service is a combination of core services and a certain number of peripheral services. These peripheral services serve to enhance the core service or to facilitate access to it, although they do not usually by themselves justify the customer's demand for the service in question. This emerging development is particularly easy to understand and frequent in the so-called "packaged" or "assembled services" services, i.e. services which are composed of the association of clearly identifiable elementary constituent services. This is the case, for example, with hospital or hotel services, retailing, tourism, theme parks, air transport etc. This emerging development includes two opposed models of innovation: a "regressive model" and an "extensive model" (Djellal and Gallouj, 2005, 2008). The regressive model consists in eliminating a part of or the whole set of peripheral services, in order to focus on core services. The extensive principle is frequently at work in diversification strategies. Extending the range of services on offer and competing on the range of services provided seem to be important elements in the strategies adopted by providers of 'assembled' services. On the other hand, it may seem paradoxical to link the terms innovation and regression. It is nonetheless the case that, in many service activities, the innovation process may follow a trajectory of reduction in service and services.

\section{Underlying drivers}

The success factor of this emerging development in its regression facet is the reduction of the cost and price structure by seeking minimum service. The main drivers underlying the two facets of this emerging development are the following ones: ICTs and other technologies, globalisation/competition and the institutional driver and also societal challenges (Figure 2). Service regression seeks for cost reduction. This is achieved by the use of labour saving technical systems and the implementation of production modes based on standardisation. This is particularly obvious in the case of Mc Donald's, and of Accor Formule 1 hotels.

ICTs play here an essential role, especially in activities (either service light or service intensive) where booking is necessary. They especially play an important role in the success of low cost airline companies, which abandoned physical point of sales and replaced them with reservation 
technical systems: e-reservation, e-ticketing, ticket-less travel. In hostelry, the French group Accor was the pioneer of the centralised reservation system, initially by phone, and now increasingly online. ICTs are the enabling technologies of innovation in financial services whatever their service content and the range of services on offer.

The institutional driver is, in certain activities, a sine qua non driver of innovation. Thus, it is deregulation policies that are the source of the creation of low cost companies in air transportation. In large scale retailing, regulation in the field of geographical location, opening hours play also an extremely important role.

As regards the competition/globalisation driver, one can often observe that both these service regressive (low cost) and service extensive formats are implemented in a context of high national or international competition. The services light formats make it possible to enter international markets and to fight against international competition in domestic markets.

\section{Manifestations of the emerging development}

In its regression facet this emerging development manifests itself in various service sectors: in air transport with low cost companies, in hostelry with budget hotel chains such as Formule 1 or Travelodge, in large scale retailing with hard discount, in catering with fast food industry, but also in many other sectors: hairdressing, gardening, mobile communication, fitness centers, funeral services, etc. Health sector also provides examples of innovations following this regressive emerging development. Indeed there are also hospitals hyper specialised in very specific types of patients, for example clinics specialised in diabetes, legs surgery or inguinal hernias. The service regressive dimension of this emerging development, it should be acknowledged, is also at work in certain manufacturing activities. This is for example the case in the automotive industry with the development of the low cost cars segment both in developed and developing countries (for example the Nano by Tata already mentioned in section 2 or the Logan by Dacia).

One of the characteristics of the low cost business models, whatever the sector of activity, is that it shouldn't only be considered in terms of competition with traditional models. Indeed, it also creates new markets. Thus, the Formule 1 hotel accommodates customers who wouldn't otherwise take a hotel (for example, lorry drivers...). Similarly, low cost airline companies exploit certain niches where major companies are absent. Therefore they provide a traffic induction. They also catch customers who were not taking planes or who were preferring trains.

Manifestations of the extension facet of this emerging development are numerous. In the case of hospitals, if we confine ourselves here to examples drawn from non-medical services in hospitals, we can mention a long list of known or less known examples: bookshops, gift shops, minisupermarkets, florists, toy shops, photographers, pharmacies, hairdressing salons, recreational activities for children in hospital, sports and fitness facilities for adults, childminding services, banks, shoe repairers, dry cleaners, travel agencies, legal advice units, photographers, etc. In the case of retailing, following old examples can be cited: packing bags at the checkouts, home deliveries and the proliferation of specialist departments and individualised services, the introduction of crèches, the introduction of financial and insurance services and the opening of travel agencies and petrol stations. Another interesting manifestation of the service extension 
logic is the rise of what is called product-related services or industrial services. These are the whole range of services provided during the production or the selling of an industrial product: pre-sales, at-sales, after-sales services and independent from sales services ${ }^{6}$ (Mathieu, 2001; Vanderwe and Rada, 1988; Davies, 2004). The source of value added is increasingly located in the peripheral service related to the product rather than in the product itself. There are numerous old or new examples of such a situation. The major part of the profits of printers or photocopiers manufacturers lies in maintenance and delivery of related products and services. Some years ago, the profits generated by after-sales services were the major part of the gross margins of car manufacturers. The success of Sony Play station 2 was primarily associated with the selling of games rather than the selling of consoles.

\section{Figure 2: Emerging development - Case 2: Service regression \& service extension}

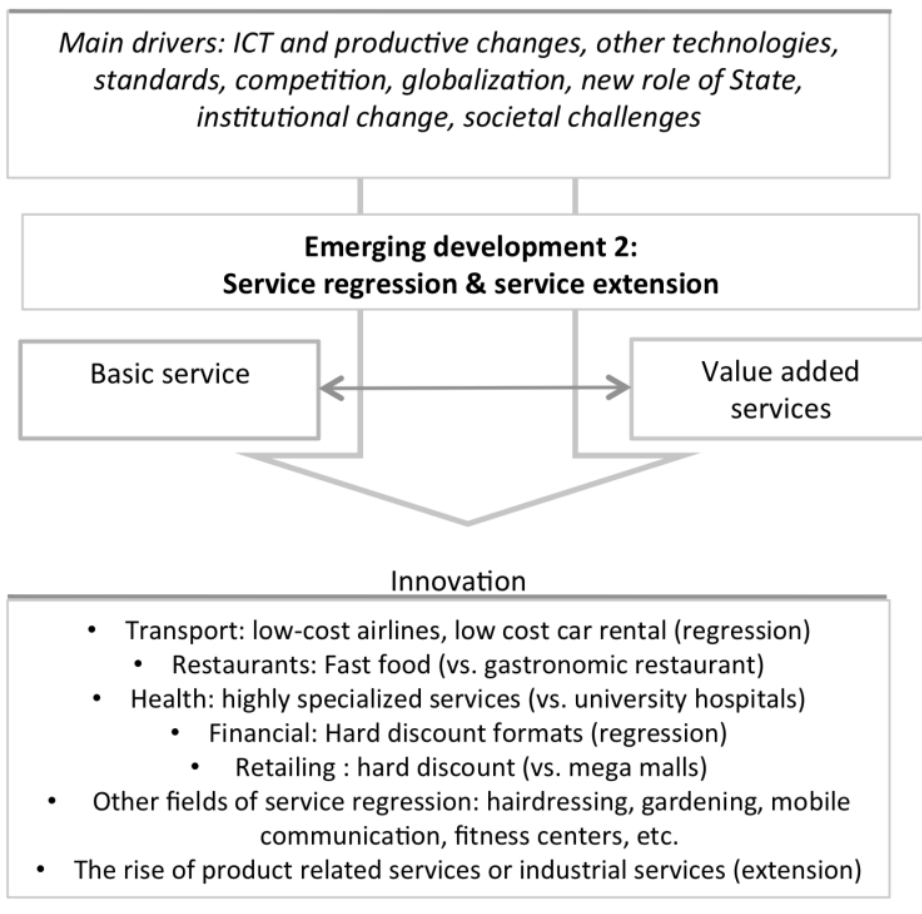

\subsection{Emerging development 3: Service innovation for an ageing society}

The essence of the emerging development

The demographic variable is an important challenge for the future of the European societies. In EU countries, it has different features, which can impact innovation: population ageing, population decrease, migrations. Eurostat's projections ${ }^{7}$ forecast a decrease of working population by 52 millions in 2050, even if migratory flows are taken into account. The same source indicates that the share of elderly (more than 65 years old people) will reach $29.9 \%$, whereas it was $16.4 \%$ in 2004. Taking care of ageing is a major societal challenge in Europe.

\footnotetext{
${ }^{6}$ These are services that are independent of the product and the production process, for example, child care, sporting and recreational services.

${ }^{7}$ Eurostat new release 48/2005-8 April 2005
} 
Service innovation is necessary to address this challenge and there is an emerging trend to reply, mainly from health services and from social services that are the two ones more in contact with the elderly.

\section{Underlying drivers}

Ageing associated to the reduction of the whole population induces new and increased needs for productivity gains in the whole economy (and not only in services). These needs mobilise the "Technology" driver. The goal is to rationalise production processes and to mobilise technical equipments in order to offset the gap of human resources thanks to robotisation and automation.

However, population ageing also means the increase of the number of wealthy people with incomes beyond the average. These people constitute an interesting market (which is sometimes labelled grey or senior market), provided supply is able to fit their particularities. In this case, innovation may be based on following drivers: customisation, marketisation (which means the market replacing traditional household production), technology adaptation associated with IT literacy. Indeed, population ageing leads to the implementation of new services and new technologies in order to meet elderly needs.

Ageing also means the increase of dependency, which is also a major source of innovations based on the same drivers (customisation, marketisation, technology adaptation associated with IT literacy). The institutional driver of course also plays an important role in such a major societal challenge (Figure 3 ).

\section{Figure 3: Emerging development Case 3: Service innovation for an ageing population}

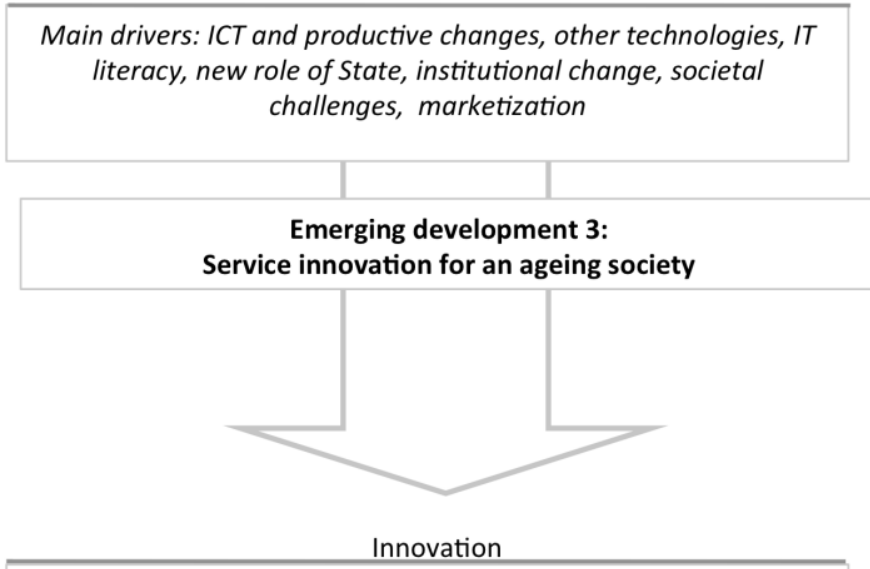

- Real Estate: new forms of residential provision for elderly

- Health: medical and non-medical technologies (intangible and intangible) e-health

- Health: care giver "burden" support innovation

- New services adapted to silver grey - could be linked to grey economy market (various sectors, care, social services, transportation, leisure services, etc.) 
This emerging development manifests itself by an important innovation dynamics triggered towards taking care of elderly. The major targets of innovation in care services for the elderly are the following (Djellal and Gallouj, 2006):

1) The structures or, more generally, the forms of assistance and residential provision (institutions, domiciliary services, networks, etc.).

2) The technologies. These are a set of tangible or intangible artefacts (technical systems, architecture and ergonomics, methods, etc.), which may have medical or non-medical purposes.

3) The human environment of the elderly, whether that be family carers or care personnel. For example, the so-called care giver burden (that is psychological, social and financial in origin) is the driving force behind various innovation trajectories, which seek either to assess the burden or to cope with it.

4) The services provided to the elderly, which vary depending on the service medium in question (the various characteristics of the elderly individuals themselves, the goods they possess or use etc.). There is considerable potential for innovation linked to this target. Virtually any existing service can be adapted to the elderly population in order to extend the range of services on offer (domestic services, care services, financial and insurance services, leisure services, transportation, etc.).

\subsection{Emerging development 4: The shift towards sustainable development}

\section{The essence of the emerging development}

A powerful emerging development, which is still at its initial step, is the emerging development based on the sustainable development question in its environmental dimension. Indeed, until recently, the service economy has developed independently of the sustainable development question, with the implicit hypothesis that (except for some of them such as transportation) services are environment friendly because of their intangible nature (Gadrey, 2010; Fourcroy et al., 2012; Desmarchelier and Gallouj, 2013).

\section{Underlying drivers}

Because of its importance, this emerging development is based directly or indirectly (and with various relationships) on anyone of the individual drivers of innovation mentioned earlier. Nevertheless, certain drivers are prominent. The globalisation driver is one of them. Indeed the sustainable development question is basically raised at the global level. It doesn't respect geographical boundaries (e.g. pollution). Another one is the demographic driver, as far as sustainable development is not only concerned with environmental issues but also with social ones. The institutional driver is also important as far as sustainable development issues need national and international policies and rules. One can also mention the technology, R\&D driver, as far as the source but also the solution of numerous environmental sustainability issues involve in this technological variable (Figure 4). 
Figure 4: Emerging development - case 4: Sustainable development

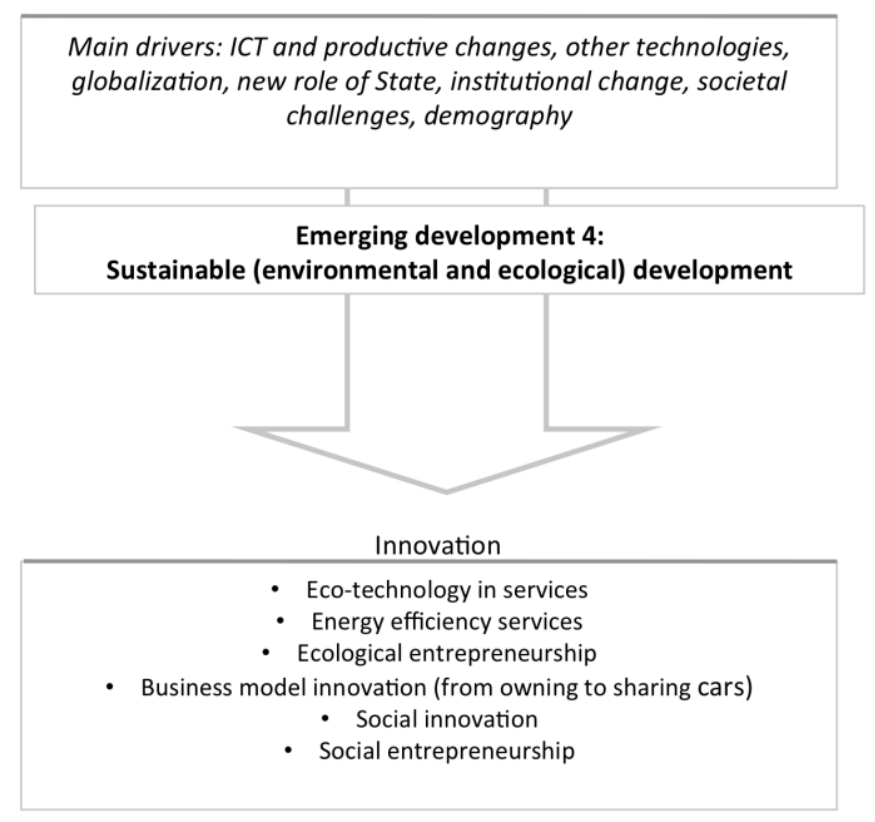

\section{Manifestations of the emerging development}

The notion of sustainable development is characterised by four interdependent biases (Djellal, Gallouj, 2010): it is industrialist, technologist, environmentalist and defensive. As an instrument of militant protest and then as a major theoretical category, it was born and grew to maturity in an environment dominated by an all-powerful manufacturing industry reliant on continuous technological innovation that impacted on the environment. Before it acquired its social or socioeconomic dimensions, sustainable development was (and continues to be to some extent) primarily ecological and environmental; its main concern was manufacturing industry's devastating effects on non-renewable resources and the environment. However (and this is a consequence of the four interdependent biases), this notion of sustainable development is also 'defensive', that is it is fundamentally concerned with the repair of damage (essentially to the environment).

These four biases persist in economies in which services are the main sources of wealth and jobs. However, services alter the terms of the sustainable development problematic. They play (and will increasingly be led to play) an important role in sustainable development, both statically and dynamically, that is through the innovations they produce or induce. It is necessary to argue in favour of a service-based approach to sustainable development, which involves a loosening of the various biases in question.

Thus it is in the dominant service sector that the future of the sustainable development question will be played out, whether positively or negatively. At the moment, a large proportion of service activities seems to have a fairly small environmental footprint compared with manufacturing industries, while at the same time producing essential socio-economic effects: it is services that generate most jobs in contemporary economies. They are also the main users of information and 
communications technologies, which are regarded as having a relatively low MIPS (Material Intensity/Per Service Unit) ${ }^{8}$.

Furthermore, non-technological (particularly social) innovation occupies an essential place in a sustainable service society. Many new services, which may possibly be delivered through new forms of entrepreneurship (and this has been recognised by public policy), are sources not only of jobs (economic solutions) but also of solidarity (services to individuals living in hardship).

Finally, whether the innovation is technological or non-technological, environmental or socioeconomic, services play an active role in the production of innovations, not only those that cure or repair damage inflicted on the environment or on individuals' socio-economic well-being but also those that are preventive and proactive (education of populations, training related to environmental norms or labels, etc.).

Overall, as stated by Gadrey (2010), the future of the service economy is also played in the environmental arena and is tightly linked to the innovation it can or cannot generate. The service relationship, which is considered one of the specificities of services, is likely to raise environmental problems, as far as it is based on displacements of consumers towards providers or vice-versa (Fourcroy et al., 2012). Furthermore the increasing use of non-environment friendly technologies by services is underestimated. This is the case of ICTs which manufacturing requires rare and polluting raw materials. An important issue at stake here is the measurement of the environmental impacts of services. Gadrey carried out a very interesting prospective work on the future of service sectors at the 2050 horizon. Taken into account sustainability constraints, he concludes that one shouldn't expect an increase in the share of services in the long term. He forecasts the decline and disappearance of whole parts of the service economy. Thus, he distinguishes winner services and loser services. According to him, loser services include: road and air transport, hostelry, catering, tourism... Winning services include repairs, recycling, maintenance services, local government, services for young children and the elderly.

\section{Emerging developments and future scenarios in KIBS and WRT}

\subsection{The significance of current drivers and emerging developments}

Based on the previous analysis of drivers and emerging developments, it is possible to project some future scenarios for particular services subsectors. While it is not useful to develop concrete scenarios for the service sector as such, due to the diversity by which the sector is characterized, individual service sub-sectors are amenable to scenario development. In this section, we will focus on two quite distinct service sub-sectors, namely Knowledge-Intensive Business Services (KIBS) and Wholesale and Retail Distributive Trade (WRT), in order to take account of the diversity of service sub-sectors while acknowledging that there are nevertheless some important commonalities between them in terms of underlying drivers and emerging developments.

\footnotetext{
8 The MIPS indicator (Material Intensity/ Per Service Unit) measures the degree of utilisation of natural non renewable resources to produce a good or a service.
} 
KIBS are a quite distinct case because they are strongly affected by the industrialisation of services and the emergence of product-related services. The role of technological change is dramatically changing the provision of KIBS. It acts as enabler of new services by creating demand for new types of knowledge, for instance in the context of research services, technical advice for dealing with complex technology issues (e.g. in IT consulting), or testing, engineering and architectural services. Besides, ICT is altering the way services are delivered. Interactive service creation between client and service provider does not need to be in the same place any more. Geographic proximity remains an important factor for the provision of KIBS, but its significance decreases because delivery of certain types of KIBS over distance becomes possible. This is evidenced by the strong growth of KIBS offshoring since 2000 even if its current statistical evidence is still not very significant (Stare and Rubalcaba, 2010). Finally, codification of formerly tacit knowledge also plays a key role: customers cannot buy the knowledge alone but it needs to be embedded in services; however, the possibility to codify increases (e.g. tax preparation programmes). This codification trend may even stop or reverse the trends towards outsourcing.

Other previously analysed emerging developments can also be identified in KIBS provision. There is an increase in health-oriented KIBS addressed to health care services. For example, some security, facility management and IT firms are entering the market of tele-assistance for elderly people and create new service products that contribute to a conversion of KIBS into consumption services. In this sense, some KIBS are becoming KIS (without the "B") as a reply to this huge societal challenge. In the field of environmental services a similar trend can be observed. KIBS are starting to address the demand for a more sustainable provision of services related to smart cities, energy consumption and cleaning industries. The trend toward service regression dynamics can also be observed in some KIBS, mainly in those countries affected by the current economic and financial crisis. Consultancy or ICT services are asked to be kept at the minimum, so the crisis is pushing towards a reduction of service offerings in many areas.

The drivers and emerging developments analysed in the previous sections are also visible in the case of WRT. Services in WRT have always been characterised by a tension between industrialisation and servicisation, and the balance is very different depending on the socioeconomic context in which this is embedded. For example, it is well know that the American culture of shopping in big malls stands in stark contrast with the more European tradition of shopping in small urban retailing shops; a situation that is also coherent with the territorial landscape on the two continents.

In the past, the growing significance of industrialisation in large retailing trade was evolving in parallel with a trend towards customisation in small retailing. Today this distinction in two separate developments is not totally true anymore. Some large stores have a strong personalisation policy offering a dedicated attention to customers and some small outlets offer a very standardised shopping. The retailing world is finding new balances between the two extremes in which new service products are produced and some regression dynamics can also be found, mainly in large stores (e.g., self-buy models with minimum or no service interaction, less services at minimum price). Other drivers of WRT are the growing internationalisation and liberalisation, the blurring frontiers between wholesale and relate, the role of ICT and logistics. In the WRT the emerging developments of providing services for an ageing population has still a minor but increasingly significant role, and sustainability is increasing in importance as far the green retailing is concerned. With regard to the latter, the trend towards more ecologically conscious and sustainable consumption is also playing a role. 
Table 1 compares the main service characteristics and emerging developments in both KIBS and WRT. It also provides examples of key elements in each sector dynamics related to the four emerging developments analysed in the previous section. The significance and impact, as well as the degree of uncertainty of these key developments, differ across sectors. They thus represent a useful starting point for exploring sector-level scenarios.

\section{Table 1: Comparative overview of service characteristics and emerging developments in KIBS and WRT}

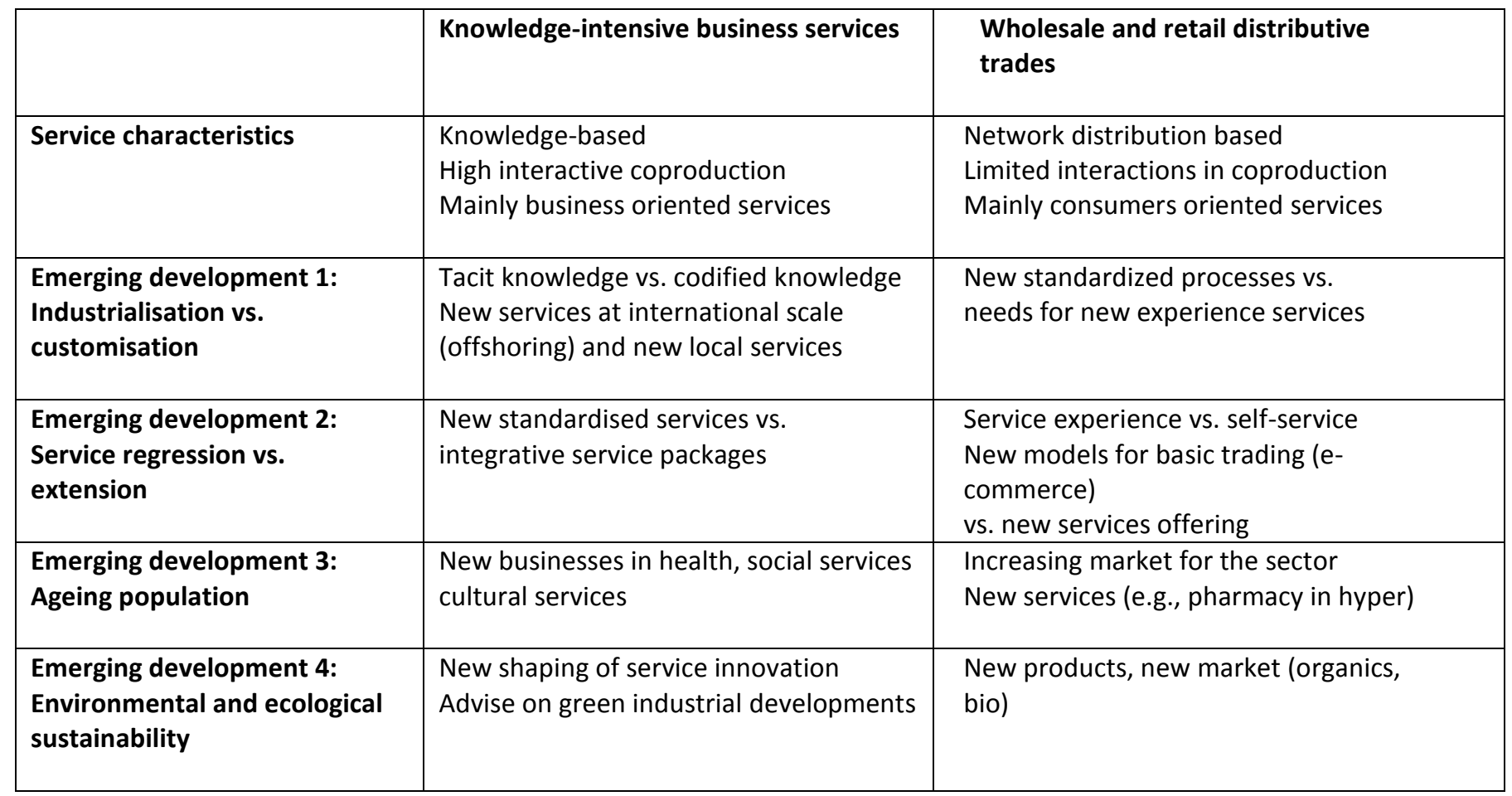

\subsection{Framework and approach for defining scenarios}

Against this general background, we will now outline different possible variants (or scenarios) of the future evolution of the KIBS and WRT sectors, based on different combinations of drivers and emerging developments in service provision. Some of the developments behind these scenarios capture specific sectoral developments, while others may come from the wider context in which the sector is embedded. The scenarios also build on some general assumptions that had to be defined in order to delimit the range of possible futures to be considered. The first of these assumptions refers to economic growth, which is expected to continue, even if the current economic crisis has introduced some uncertainty about the short-to mid-term growth perspectives. It may not evolve at a rate similar to the past, but is likely to be more modest. In any case, since KIBS depend on their client industries and WRT on their final customers, this means that demand for both sub-sectors is expected to increase as well.

Second, technological change in information and communication technologies is expected to continue at considerable speed. This means that new technological opportunities will open up for instance for new ways of automated service delivery, but also new technological opportunities to 
support creativity and communication. This may completely change the way of service provision in the future because of a higher acceptance of Internet-based service provision and communication over distance.

Finally, policy measures such as regulation and restrictions to market access will in the future not seriously hamper service growth outsourcing and international trade in services in both subsectors,. As regards KIBS, regulation may even trigger further demand, because it creates new demand for advice (e.g. in environmental consulting services).

KIBS and WRT are very distinct service sub-sectors, but their future evolution is shaped by the same drivers and cross-cutting developments in services. It is thus possible to draw an analytical framework that integrates the different scenarios from the two sub-sectors, on the grounds that they refer to the same distinctive dimensions. The analytical framework for defining the scenarios is illustrated in figure 5. The drivers of the services growth and the emerging developments affecting the future of services are based on a combination of contextual factors and sectorally specific factors, thus defining different scenarios. As regards the contextual aspects, it is useful to distinguish stable from dynamic scenarios, with the latter being characterised by a high pace of change and strong demand drivers.

Complementary to the distinction between highly dynamic and comparatively stable scenarios, there are further sectoral issues to be considered. One important sectoral issue, mainly affecting KIBS is the contraposition between tacit knowledge and codified knowledge. This is reflecting to some extent the tension between industrialisation and customisation emerging development that is leading to new balances in the services economy. Some KIBs are highly customised and in dynamic scenarios they can become extremely creative and interactive. Other KIBS are currently producing a rather automatic delivery but in dynamic scenarios they can offer more exploratory research environment.

In WRT, the scenarios can be distinguished at sectoral level with regard to the dominant mode of service experience. It makes a difference whether the consumer participates in a full service experience beyond the mere shopping, or if the consumer is addressed to self-consumption and a digital consumer role. WRT scenarios can also be classified in more or less stable ones, depending on whether the exploitation of local markets and the implementation of the big boxes model represent different ways to solve the industrialisation and customisation dialectic (e.g., local markets may become more accessible and customised), or whether they represent specific cases of service regression (e.g., making cheaper the service by reducing some service characteristics like diversity).

The methodology for scenario development was conceptually inspired by the approach of sectoral innovation system foresight (Weber et al. 2009). This approach takes the concept of Sectoral Systems of Innovation and Production (SSIP, Malerba 2005) as its conceptual basis. The main elements to be considered in the SSIP framework are actors and networks, knowledge and technologies, and institutions. Emphasis is also put on the importance of the demand side for the dynamics of SSIP. These elements are regarded as co-evolving to give rise to system change.

In process terms, scenario development followed a multi-stage process to explore the future of SSIP. Based on thorough innovation system analysis, capturing the current situation of the sector along the lines of the heuristic model, internal and external drivers and emerging developments were explored. These drivers could be of various kinds, ranging from scientific-technological developments to wider socio-economic developments affecting the demand side of innovation. 
The intersection of different such drivers and developments led to the identification of innovation themes and subsequent considerations regarding emerging markets for these innovation themes. Finally, a critical analysis was conducted of the requirements that need to be in place for the combination of innovation themes and emerging markets to be realised. These requirements could be of various kinds. They include actor strategies and organisational requirements at firm level, skills and knowledge needs, but also structural changes to the configuration of actors in a sector, inter-dependencies with developments in other sectors, or institutional changes determining the interactions between the main players in a sector. The individual scenarios are then plausible combinations of these co-evolving elements.

Core to the scenario development, and fed by corresponding briefing papers, were two major stakeholder workshops, bringing together experts from industry, research, government and civil society to specific drivers and innovation themes (workshop 1) and to develop the initial scenario sketches (workshop 2). The final draft scenarios were subsequently validated by the workshop participants in a written procedure. The final scenarios developed were thus neither purely exploratory, nor strongly normative, but represent a cross-section of plausible and internally consistent futures, reflecting combinations of desirable and less desirable outcomes.

\section{Figure 5: Scenarios for KIBS and WRT: a framework}

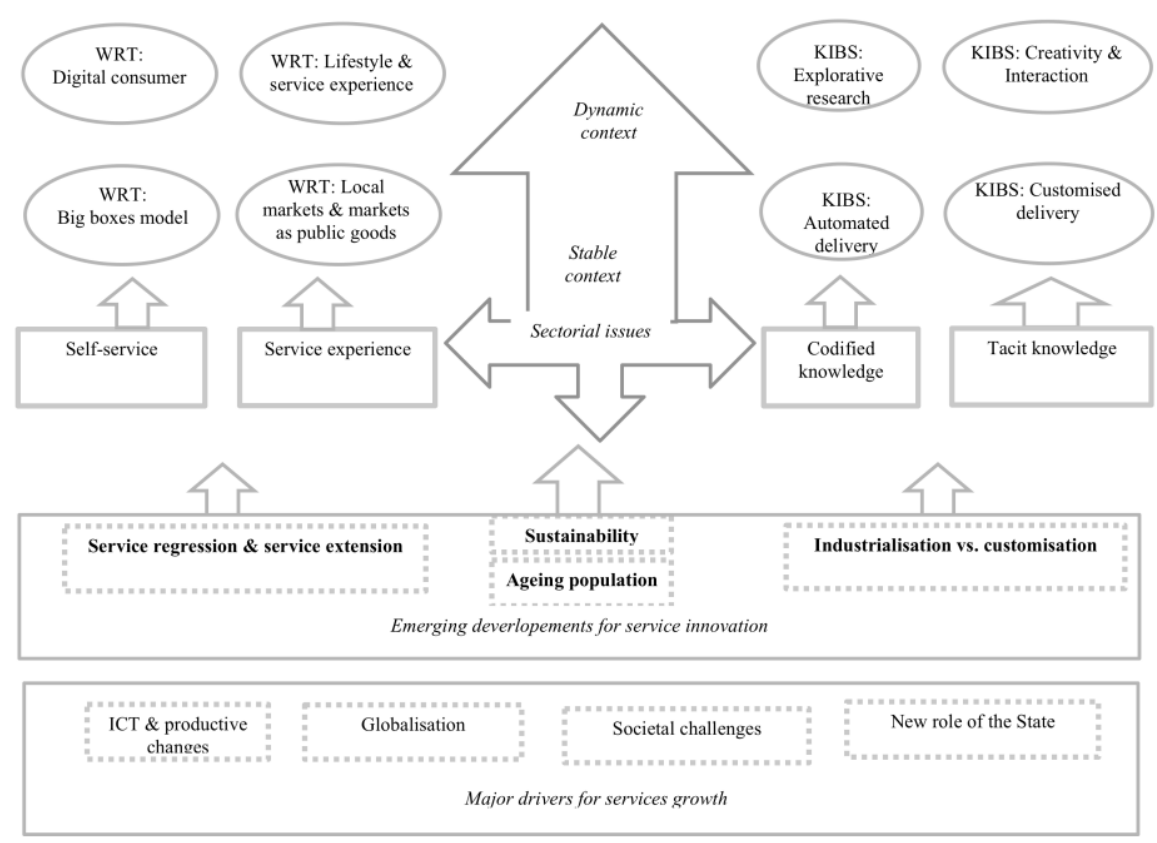


While thus being developed in a bottom-up fashion, using drivers and emerging developments as a starting point rather than pre-given starter scenarios, the overall final presentation of the resulting scenarios is inspired by the GBN scenarios framework done along the lines of two key distinctive dimensions that are characterized by a particularly high degree of uncertainty and potential impact. One of the two main dimensions is shared between KIBS and WRT and refers to the extent to which the scenarios are embedded in a highly dynamic or a rather stable context. The other distinctive dimension refers to sector-level developments, namely the degree of tacitness vs. codification of knowledge in the case of KIBS, and to the orientation towards service experience vs. self-service in the case of WRT. Two out of the five WRT scenarios (Scenario 'Local Markets' and Scenario 'Markets as Public Good') can be located roughly in the same quadrant of this two-dimensional framework, but differ in a number of other regards. The positioning of the scenarios in this framework, together with the underlying drivers and emerging developments is illustrated in figure 5.

\subsection{Scenarios in KIBS}

KIBS have been the object of several future oriented investigations in the past, including some scenario development exercises. The findings of these earlier projects were taken into account and fed into the scenario workshops conducted. ${ }^{9}$

\section{Scenario "Customised delivery"}

The first scenario, which is characterized by a combination of a high degree of tacitness and a stable environment is closest to established picture of consultants: internal experts who, on a long-term basis, contribute to innovation and the provision of services at their clients. A characteristic of this scenario are stable supplier-client relationships which may be a good environment to codify knowledge. In our scenario, however, innovation is very much ad-hoc, involving co-production and creativity-based activities, so the opportunities for codification remain low despite the favourable environment. Growth of KIBS in this scenario will be a prolongation of the trend we have observed over the last 30 years; KIBS will play an increasing role in the innovation processes of their clients, fuelled by specialisation and cost advantages, and by the trend towards outsourcing. KIBS are provided by firms, rather than individual experts, who have a long-term relationship with their clients.

\section{Scenario "Creativity \& interaction"}

The combination of a high degree of tacitness and a dynamic environment results in a scenario where innovation activity is very much interactive and an industry structure that is fluid. Cooperation is often not very deep - information rather flows through 'weak ties' rather than yearlong co-operation. Activity is mostly project-based and rests on individual people and their expertise rather than on the institutionalized firms. This scenario may be close to what is currently discussed as "open innovation". KIBS are often facilitators, by providing platforms to support exchange. Collaboration between university researchers or people in the creative industries are an example for how actors acquire projects and join together for different tasks in this scenario.

${ }^{9}$ See Miles (2005), Miles et al. (1994), Toivonen (2004), Kox (2002). The detailed results of the scenario development work can be found in Dachs (2010). 
This scenario implies a high degree of openness and a vivid exchange of ideas, which may bring forward new solutions to problems and a higher innovativeness in general. We may also assume that this scenario will bring considerable growth potentials for KIBS because their integration into the innovation processes of client industries is easy in this scenario. The likelihood of this scenario may also be limited by different factors: first, security concerns of the partners. A second possible limitation is information asymmetry and the degree services are standardized; it is easier to co-operate in a loose way when one knows what he/she can expect from the partner. Moreover, the local character of KIBS should be diminished in this scenario, where co-operation is virtually 'distance-free'.

\section{Scenario "Explorative research"}

This scenario is characterized by the combination of a low degree of tacitness and a dynamic environment. As a result, we see more opportunities for codification and a more decisive role of ICT for service provision. This will lead to a considerably higher degree of automatisation in this scenario. As a result, personal expertise will be a far less critical factor for service provision than in the previous scenarios. Instead, the services are much more based on ICT and software, for example on data mining. One recent example for this mode of service provision is Google.

Growth prospects for KIBS are again favourable in this scenario, because it assumes a high degree of openness, user involvement and a more user-driven mode of innovation. Moreover, there may also be considerable growth prospects from the technology side, because the scenario assumes rapid progress in the codification of services which may lead to increasing returns to scale and decreasing unit costs of service provision. In contrast to the previous scenario, this clearly favours large firms. The growth of KIBS, however, may be hampered by more in-house service provision and do-it-yourself, which may pose a serious competition to external service providers. Knowledge codified in business software and tool-kits can, of course, also be used to enhance the competencies of internal departments and enable them to provide services that have been bought from external providers before.

\section{Scenario "Automated delivery"}

This scenario results from a combination of a low degree of tacitness and a stable environment. It shares the importance of ICT for service provision with the previous scenario. Co-operation in this scenario, however, is much more closed, the number of partners is smaller, and R\&D and creativity proceeds in more stable, routinized way. Services are provided in the context of firms, but projects are nevertheless important. An example for this mode may be Internet-based banks, another is Amazon.

This scenario is very similar to the "Explorative research" scenario with respect to growth prospects of KIBS. In contrast to "Explorative research", however, growth will mainly arise from codification, facilitated by the use of ICT. It will benefit considerably from cost degression, and only to a lesser extend from an expansion of KIBS involvement in the innovation processes of client industries. We may also see a considerable increase of do-it-yourself, business software and tool-kits in this scenario, which may work opposite to the growth impetus from codification.

\section{Discussion}

KIBS are a heterogeneous group of service industries. Therefore, the four scenarios should not be seen as mutually excluding variants of possible futures, but as existing side by side, or even combinations of them in specific sub-sectors. Firms that are characterized by different scenarios 
may even be found in one sector. And some KIBS-subsectors can be regarded as emblematic for different scenarios. The "Creativity \& interaction" scenario, for example, is best represented by the branding/advertising sector, while the current mode of service provision in professional and consultancy services fits best with the "Customised delivery" scenario.

The four scenarios may also be interpreted as different stages in the industry life cycle. In this process perspective, we may interpret the four scenarios as a movement from creative, unstructured and fluid beginnings to the formation of a mature and stable industry. The moves thus go mostly, but not necessarily, from a dynamic to a stable environment, in particular from customised to automated delivery and from "Creativity \& interaction" to research services. Banking, for example, had many features of the "Creativity \& interaction" in its beginnings in the 18 th and 19t century. Today, it has reached the "automated delivery" scenario with a massive investment in ICT a number of highly standardized, automated services such as Internet banking, ATM services, or credit card payment systems. It is also important to consider that KIBS growth is highly dependent on the demand of their client industries and hence from the stage of the life cycle of its clients. In other words, the stage of development for a KIBS sub-sector (new, growth, mature) depends on the life cycle of its client market. Overall, there is also a considerable heterogeneity in the life cycle of client markets of KIBS, which adds another dimension to the scenarios and contributes to overall heterogeneity of the sector. New or mature clients markets are not restricted to one, but are found in all four scenarios. Examples are the client markets for innovation agencies, e-government or sustainability consultancies, which are all at the beginning of their life cycle.

\subsection{Scenarios in Wholesale and Retail Trade}

In contrast to KIBS, Wholesale and Retail Distributive Trade has hardly been addressed by systematic forward-looking investigations. Our exploratory analysis can thus draw on very few studies only ${ }^{10}$. However, similar to KIBS, the sector is also characterised by a great deal of diversity.

The landscape of retailing and wholesale is in great flux: below, five different scenarios for possible future developments within the wholesale and retail distributive trade sector in Europe are depicted, highlighting different directions in consumer preferences and choice as well as developments forced by a small number of powerful players within the sector. Each scenario is a different version of what main parts of the retail and wholesale sector could look like in the future.

\section{Scenario "Big Boxes Everywhere \& Green Big Boxes Everywhere"}

In this scenario, discounters, supermarkets, hypermarkets, and the retail chains are omnipresent. Production and distribution are efficient and the high competition between retail chains forces the retailers to lower costs. Because of the limited number of retail chains the city centres across Europe are looking more or less all the same and the diversity of goods is also limited. In the outskirts of towns large supermarkets are targeting car owners. Retailers are entirely in the lead of what they offer in their 'big boxes' (that also can be small boxes of big retail chains) and they define what producers have to produce. Retailers are focused on providing relatively low cost

${ }^{10}$ See van der Giessen (2009) and in particular Giesecke and Schaper-Rinkel (2010) on which this section is based. 
options, achieving economies of scale and bundled products and services. The chains develop their own brands, most producers are therefore invisible, some other trusted brands have survived and prospered. The producers are dependent on one or a few large retailers who are cutting the prices constantly.

\section{Scenario "Local Markets - connected through the web"}

In this scenario, local markets are strongly based on products that could be produced locally. Because of strategies to reduce environmental impact and ensure continued economic support of farmers and local communities everywhere, local communities in Europe are interested in direct trade with developing countries. There is more local community based trade between communities in different parts of the world aiming at bypassing established retail supply chains. At the same time these local markets could be linked through web-based networks, establishing a worldwide community of local market actors with the aim of optimizing logistics, sharing knowledge on crafts, green production and cooperation. Brands would be less powerful, but labels that ensure high environmental and social standards will be more influential. Local companies and local entrepreneurs benefit from local markets where market entry is easier for them. Direct communication at the local level offers more immediate and direct consumer feedback that could be used to further develop local retail formats. High transportation costs combined with high awareness of sustainability issues and new forms of online-cooperation are the main drivers that could lead to the rise of "Local markets".

\section{Scenario "The Digital Consumer"}

In this scenario the common internal market for e-commerce is fully realized and shopping takes place through e-commerce. Online shopping and physical shops are combined in various ways: Companies are presenting their products online and they organize shops and events where consuming and shopping is embedded in spectacular events. Tools for virtual experience have been developed and consumers can learn about products from the experience of interacting with objects, people, and the environment. Producers of niche products are expected to benefit from this scenario because they get easy access to consumers and they can use the new opportunities of social networks. The growing use of the online retail by consumers and retailers enables the development of hybrid business model combining virtual and physical market presence. In regard to this scenario it is crucial to address the rise of retail-relevant giant Internet-services that were established outside Europe (Google, Amazon, Facebook, Twitter, Second Life). Otherwise European producer, retailer and wholesaler are dependent on innovation outside their scope.

\section{Scenario "The rise of Lifestyle Stores and Malls"}

Providing more customer choice to meet changing lifestyle preferences is the defining driver in the "lifestyle store" scenario. In this scenario people are mainly searching for a stimulating shopping experience. This could be provided by everything from an onsite eco-farmers' market to a blend of high-tech entertainment and shopping facilities. Lifestyle shopping malls can include one or more buildings forming a complex of shops representing merchandisers and service providers that represent the special lifestyle. Consumers benefit from lifestyle malls because they receive greater diversity of choices in one place and they can get new combinations of products and services based on their specific lifestyle. Retailers and service providers can bundle products and services and it is easy for them to further develop their products and services because they act in a setting, where they share core values of production and consumption with 
their customers and the companies they are surrounded by. The lifestyle oriented agglomeration of producers and customers could give new market perspectives for specialized producers and services providers that would otherwise not have access to a sufficient quantity of partners and potential clients. The result of this trend could be an intensification of socio-spatial segregation in European regions and polarization of lifestyles between different groups of society.

\section{Scenario "The supermarket as a public good"}

This scenario may arise if values in regard to shopping are radically changing the retail and wholesale landscape. In this scenario the main kind of distribution is a type of supermarket that is owned by society not by any individual or by a company. It pursues democratic value and gives more freedom of choice to the consumer - but also more responsibilities. It operates not primarily to maximize profits but to fulfil ethical values and to support the reshaping of society towards more sustainability and societal soundness. Consumers may benefit from the supermarket as a public good because they can make the experience to take their life into their own hands. This kind of supermarkets could keep the key collective function of providing a place of social integration at the local level. As part of community building at the local level it could serve as a mechanism supporting social cohesion. It could lead to more socially and ecologically conscious consumption and force all companies alongside the supply chain to ensure transparency. In this scenario the activities of retail and wholesale companies would be restricted and the pace of innovation would be slower. Yet, this could lead to higher intensity in social innovation.

\section{Discussion}

Across the different scenarios some issues are identified, that are of high importance for a more efficient and sustainable WRT sector. First of all, transparency in regard to the environmental and social impact of different retailers and retail services would allow consumers to make informed choices while stimulating innovation and diversity in regard to retail services. The transition to an efficient and sustainable WRT sector can have a high leverage effect on related sectors and thus contribute to a change towards more sustainable product and production characteristics in the upstream segments of the supply chain.

Secondly, the relationships between consumers and retailers are changing significantly, not the least under the influence of Web 2.0 applications and new forms of customer relations management. Informed customers who are endowed with the necessary IT skills can play a much more active role in customising products.

Thirdly, e-commerce but also Web 2.0 applications have the potential to significantly change the power balance along the supply chain. Whether this will happen, however, is highly uncertain, and thus an important lever to influence the future evolution of the WRT sector.

\section{Concluding remarks}

The pervasive role of services in structural transformation in the last decades coupled with the rapid technological progress create increasing complexities in societies that raise uncertainties about future developments. Futures studies of service economy are helpful in addressing and anticipating these developments, with a view to inform stakeholders about the drivers, emerging developments and possible scenarios at a level of specificity that is suitable for strategic action. Due to the diversity of service sectors, the level at which meaningful advice can be given corresponds to individual service sectors (such as KIBS or WRT) rather than to the service sector 
in general. Forward looking analysis can assist individuals, business sector, institutions and the policy sphere to better prepare for the future and look for potential opportunities and threats. To this end, major drivers of change, have been examined, in order to extract those that are likely to exert a strong influence on emerging developments and innovation in the service economy in the medium term (2020). It is worthwhile observing that the spotted drivers (ICT and skills, globalisation, societal and environmental challenges and the new role of state) are highly interconnected making it difficult to isolate their impacts from one another. The spotted drivers among other possible ones - have a particularly important role in shaping the emerging developments in service innovation.

When the interplay of drivers results in radical socio-economic changes that have long-term implications and affect a number of actors on a global scale, then important developments are likely to emerge which will significantly change the provision and use of services. We illustrate the directions in which emerging developments influence innovation in services and the transformation of service economy by a limited number of cases. The first one, dialectic relationship between industrialisation and customisation - emerging development gained new momentum with the pervasive applications of IT and IT literacy. The second one (service regression vs. extension) includes the particular case of the service regression dynamic indicating that service innovation does not have to result in services of better quality, but still satisfy the demand of segmented customers or even attract customers that could not afford to pay for "normal" service. In emerging market economies those innovations are referred to as frugal innovations ${ }^{11}$. Ageing as another emerging development implies innovation in various fields from the need to increase the productivity due to the gap in human resources, new business models, adapting the supply of goods and services to differentiated segments of ageing population to providing various services accommodated to elderly population (e.g. health, social and caring services, leisure, etc.). A powerful emerging development, which is unfolding rather rapidly, refers to sustainable development where services are mostly considered environment friendly (which is questionable) on account of their intangibility. Besides, various services will provide viable solutions (innovations) for improving the energy efficiency and decreasing the environmental footprint, for mitigating the damage inflicted on the environment or on individuals' socio-economic well-being.

It could be expected that the effects of the above-mentioned drivers and emerging developments will have a profound impact on services and innovation in services, but will vary for individual service sectors that are very heterogeneous. To bring meaningful results the foresight analysis needs to be performed for each group of services activities that share common features, a task that goes beyond the scope of the present analysis. We have however selected knowledge intensive business services (KIBS) and wholesale and retail trade (WRT) to illustrate possible future developments with scenarios. These two sectors differ fundamentally in regard of skills requirements, knowledge intensity, degree of customisation and standardisation, value added per employee, capital intensity, degree of internationalisation, etc.

Scenarios presented for KIBS are characterized by a combination of the two drivers: type of environment (stable vs. dynamic) and properties of knowledge (tacit vs. codified) that result in

${ }^{11}$ By that is meant the production of goods and services that are not of the best quality but that are affordable. 
four differentiated variants. Acknowledging the fact that KIBS are a heterogeneous sector, the four scenarios should not be considered as mutually exclusive potential futures, but as co-existing variants, or even as combinations in certain sub-sectors. The interpretation of these scenarios may also go along the stages of industry life cycle where dynamic environment migrates to more stable one such as for example the transition from customized to automated delivery of KIBS. Furthermore, life cycle of client markets of KIBS may also bring additional diversity to future development of KIBS sub-sectors.

In wholesale and retail trade (WRT) the demand side factors and accommodating to further segmentation of consumers along different characteristics (age, income, lifestyle, behavior related to environment and sustainability) are bound to play a decisive role in the future. Five scenarios tend to reflect the interaction of both internal and external drivers that will shape future WRT developments. Scenarios range from "big boxes" representing chains of supermarkets and hypermarkets, "local markets", "digital platforms" to "lifestyle stores". In all of them, the footprint of the most important drivers is clearly visible.

When comparing the scenarios in the two selected service sectors, it becomes obvious that the impact, but also the degree of uncertainty, of the main emerging developments in service innovation differ across sectors. Some emerging developments, such as those related to demographic and sustainability aspects, play a quite clear and trend-like role for both KIBS and WRT. Others, in particular service regression vs. extension and industrialisation vs. customization, not only differ in terms of their respective significance for KIBS and WRT, but are also characterized by a high degree of uncertainty, thus giving rise to alternative scenarios. For KIBS, the industrialisation vs. customisation issue is of particular importance, whereas for WRT the service regression vs. extension aspect gives rise to alternative scenario features.

The exercise of presenting drivers, emerging developments and scenarios serves three main purposes. Firstly, it helps to better understand the background of challenges for the services economy in Europe: the thorough analysis of drivers, emerging developments and scenarios shows that services face the challenges in a dynamic and transforming world characterized by many uncertainties. Secondly, it points out the areas where an in-depth research and analysis is needed to improve our understanding of phenomena and of their impacts (e.g. the dynamics of 3D printing adoption for related services and new business models; the expansion of e-schools accessed via mobile, social innovation linked to inclusive innovation, etc). Finally, it informs policies about early signals of forthcoming trends in service economy that need to be taken into account in designing appropriate and efficient responses for the implementation of sustainable innovation policies in the period to 2020 and beyond.

\section{References}

[1] G. Barone, F. Cingano, Service regulation and growth: Evidence from OECD countries, Temi di discussione Working Papers, 645 (2008).

[2] H. Chesbrough, K. Schwartz, Innovating Business Models with Co-Development Partnerships, Res. Technol. Manage, 50(1) (2007) 5559.

[3] J. F. Coates, J. The future of foresight - A US perspective Original Research Article, Technol. Forecast. Soc. Change 77(9) (2010) 14281437. 
[4] B. Dachs, Sectoral Innovation Foresight. Knowledge-Intensive Business Services, Final Report, Europe INNOVA, Sectoral Innovation Watch, AIT, Vienna (2010).

[5] A. Davies, Moving bas into high-value integrated solutions: a value stream approach, Ind. Corp. Change 13 (2004) 727756.

[6] De Reuver, M., Bouwman, Prieto, G., and Visser, A., Governance of flexible mobile service platform. Futures, 43(9) (2011) 979985.

[7] B. Desmarchelier, F. Gallouj, Endogenous growth and environmental policy: are the processes of growth and tertiarisation in developed economies reversible? An evolutionary perspective, J. Evol. Econ. 23(4) (2013) 831860.

[8] F. Djellal, F. Gallouj, Innovation in care services for the Elderly, Serv. Ind. J. 26(3) (2006) 303327.

[9] F. Djellal, F. Gallouj F., Innovation in services and sustainable development, in P.P. Maglio, C.A. Kieliszewski, J.C. Spohrer (eds), The Handbook of Service Science, Springer, Berlin, 533-557, 2010.

[10] F. Djellal, F. Gallouj F., Mapping innovation dynamics in hospitals, Res. Policy 34 (2005) 817835.

[11] F. Djellal, F. Gallouj, A model for analysing the innovation dynamic in services: the case of architectural-type services, Int J. Serv Tech. Manag. 9(3/4) (2008) 285304.

[12] European Commission, Innovation Union Competitiveness Report 2013, Towards knowledge driven reindustrialisation, Commission staff working document SWD(2013)347 final (2013a).

[13] European Commission, Euopean Union, Sectorial Innovation Watch. Final Report. http://ec.europa.eu/enterprise/policies/innovation/support/europe-innova/index en.htm (2013b).

[14] European Commission, EU DG Enterprise. Europe Innova. Towards a European Strategy in Support of Innovation in Services. Challenges and Key Issues for Future Actions. (2007).

[15] European Parliament, European Parliament resolution of 15 June 2010 on the Internet of Things, (2009/2224(INI)) (15.06.2010) (2010).

[16] C. Fourcroy, F. Gallouj, F. Decellas, Energy consumption in service industries: challenging the myth of non-materiality, Ecol. Econ. 81 (2012) 155164.

[17] J. Gadrey, The environmental crisis and the economics of services: the need for revolution, in F. Gallouj, F. Djellal (eds), The handbook of innovation and services: a multi-disciplinary perspective, Edward Elgar, Cheltenham 93-125, 2010.

[18] F. Gallouj, Innovation in the Service Economy: The New Wealth of Nations, Edward Elgar, Cheltenham, U.K. and Northampton, Mass., 2002.

[19] S. Giesecke, P. Schaper-Rinkel, Sectoral Innovation Foresight. Wholesale and Retail Services, Final Report, Europe INNOVA, Sectoral Innovation Watch, AIT, Vienna (2010).

[20] M. Godet, From Anticipation to Action, A Handbook of Strategic Prospective, UNESCO Publishing, 1994.

[21] M. Godet, Creating futures, Scenario Planning as a Strategic Management Tool. Economica, Paris, 2006.

[22] T. Kuosa, Futures signals sense-making framework (FSSF): A start-up tool to analyse and categorise weak signals, wild cards, drivers, trends and other types of information, Futures 42 (1) (2010) 4248. 
[23] H. L. M. Kox, Growth Challenges for the Dutch Business Services Industry. International Comparison and Policy Issues. The Hague: CPB Netherlands Bureau for Economic Policy Analysis (2002).

[24] F. Malerba, Sectoral systems of innovation: a framework for linking innovation to the knowledge base, structure and dynamics of sectors, Eco. Innov and New Tech. 14(1) 20056382.

[25] B.R. Martin, R. Johnston, Technology foresight for wiring up the national innovation system: experiences in Britain, Australia, and New Zealand, Technol. Forecast. Soc. Change 69 (1999) 3754.

[26] V. Mathieu, Service strategies within the manufacturing sector: benefits, costs and partnerships, Int. J. Serv Ind. Manag, 12(5) (2001) 451475.

[27] McKinsey Global Institute, Beyond austerity: A path to economic growth and renewal in Europe, MGI report, October (2010).

[28] I. Miles, The development of technology foresight: A review, Technol. Forecast. Soc. Change 77 (2010) 14481456.

[29] I. Miles, Knowledge Intensive Business Services: Prospects and Policies. Foresight 7(6) (2005) 39 63.

[30] I. Miles et al., Knowledge-Intensive Business Services: Their Role as Users, Carriers and Sources of Innovation, Manchester: PREST, Manchester University (1994).

[31] F.J. Milliken, F.J., Three types of perceived uncertainty about the environment: state, effect, and response uncertainty, Acad. Manag. Rev. 12 (1987) 133143.

[32] J. Naisbitt, Megatrends: Ten new directions transforming our lives, Warner Books, 1982.

[33] G. Nicoletti, S. Scarpetta, Regulation, productivity and growth, World Bank Policy Research Working Paper, No. 2944 (2003).

[34] F. Phillips, The state of technological and social change: Impressions, Technol. Forecast. Soc. Change 78 (2011) 10721078.

[35] C.K. Prahalad, R.A. Mashelkar, Innovation's Holy Grail, Harvard Business Review, July - August (2010) 132141.

[36] M. Puglisi, The study of the futures: an overview of futures studies methodologies, in Camarda D, Grassini L. (eds.) Options Mediterranées, Series A 44 (2001) 439463.

[37] L. Rubalcaba, The New Services Economy: Challenges and Policy Implications for Europe, Edward Elgar, Cheltenham, 2007.

[38] O. Saritas, J.E. Smith, The Big Picture - trends, drivers, wild cards, discontinuities and weak signals. Futures 43(3) (2011) 292312.

[39] O. Saritas, Y. Nugroho, Mapping issues and envisaging futures: An evolutionary scenario approach, Technol. Forecast. Soc. Change 79 (2012) 509529.

[40] ServPPIN, The contribution of services to economic growth and welfare and the role of publicprivate innovation networks. Final report. EU 7FP project. www.servpppin.com (2011).

[41] D. Sharman, Indian IT outsourcing industry: future threats and challenges. Futures. On line version 17 October 2013.

[42] R. Slaughter (ed.) New Thinking for a New Millennium (Futures and Education Series). Routledge, 1996. 
[43] M. Stare, L. Rubalcaba, International Outsourcing of Services: What Role for Central and East European Countries? Emerg. Mark. and Trade 45(5) (2010) 3146.

[44] M. Toivonen, Expertise as Business. Long-term Development and Future Prospects of Knowledgeintensive Business Services (KIBS). Helsinki University of Technology, Espoo (2004).

[45] D. Tow, Future planet - the future of services, International Social News Agency, 15 October (2012) http://www.international.to/index.php?option=com_content\&view=article\&id=7005:future-planet--thefuture-of-services\&catid=94:david-tow\&Itemid=104

[46] A. van der Giessen, G. Gijsbers, D. Maier and F. van der Zee, Trends, Developments and State-ofPlay in the Distribution and Trade Sector in the EU, Final Report (2009).

[47] S. Vanderwe, J. Rada, Servitization of business: adding value by adding services, Eur. Manag. J. 6(4) (1998) 314324.

[48] R. Vecchiato, C. Roveda, Strategic foresight in corporate organisations: Handling the effect and response uncertainty of technology and social drivers of change, Technol. Forecast. Soc. Change 77 (2010) 15271539.

[49] M. Weber, P. Schaper-Rinkel, M. Butter, Sectoral Innovation Foresight. Introduction, Interim Report, Europe INNOVA, Sectoral Innovation Watch“, AIT, Vienna (2009).

[50] WIR (World Investment Report), Investing in a low-carbon economy, WIR United Nations (2010).

[51] WIR (World Investment Report), Towards a new generation of investment policies, WIR United Nations (2012).

\section{Authors}

Faïz Gallouj, Professor, Faculty of Economics and Sociology, Department of Economics, University Lille 1, CLERSE-CNRS, France.

Matthias Weber, Deputy Head of Department, Austrian Institute of Technology (AIT), Foresight and Policy Development Department, Austria.

Metka Stare, Research Professor, University of Ljubljana, Faculty of Social Science, Slovenia.

Luis Rubalcaba, Professor, University of Alcala, Applied Economics Department, Spain. 